\title{
Some Ethnic Features of Northern Aborigines' Psychophysiology as a Base for Survival in Extreme Natural Conditions: A Review
}

\author{
V. I. Hasnulin1, I. M. Voytik², A. V. Hasnulina1, T. I. Ryabichenko1, G. A. Skosyreva1 \\ ${ }^{1}$ Research Center of Clinical and Experimental Medicine SB RAMS, Novosibirsk, Russia \\ ${ }^{2}$ Siberian Institute of Management, Russian Academy of National Economy and Public Administration under \\ the President of the Russian Federation, Novosibirsk, Russia \\ Email: hasnulin@ngs.ru
}

Received 18 April 2014; revised 18 May 2014; accepted 18 June 2014

Copyright (C) 2014 by authors and Scientific Research Publishing Inc.

This work is licensed under the Creative Commons Attribution International License (CC BY). http://creativecommons.org/licenses/by/4.0/

(c) (i) Open Access

\section{Abstract}

The indigenous population of the North can efficiently preserve health and vital activity, and reproduce new generations under extreme climatic and geographic conditions due to peculiar way of life, mental features, rituals, regimes of work and rest, social and cultural traditions. Of great importance are also the clothes which are favorable for keeping heat and self-cleaning, some psycho-therapeutic factors (rituals of shamanism), animal food and vegetables. The phenotype of the adaptation reserves of an organism, northern type of metabolism, dominance of the right brain hemisphere play a great role, so does the adaptation of national mentality to the harmony of inner human state with the extreme environmental conditions of high latitudes.

\section{Keywords}

Psychophysiological Mechanisms of Survival, Phenotype of Organism Adaptation Reserves, Hemispheric Asymmetry, Northern Type of Metabolism

\section{Introduction}

Considering the psychology and psychophysiology of any ethnic group, especially at the current stage, it is necessary to note its close dependence on climatic and geographic conditions of the region of its residence. The very notion of ethnicity, according to many opinions, should be treated in three aspects-climatic and geo- 
graphic, anthropological and biological, and socio-cultural [1]-[7].

Sukharev's research [8]-[10] gives grounds to say that the priority factor of human mental ontogenesis is the natural birth and residence environment. Correspondingly, a "starting-point" in the diagnostics of ethnofunctional disontogenesis is the discrepancy of socio-cultural and anthropological and biological characteristics with landscape and climatic conditions.

Up to now, there have been no scientific publications summarizing the ethnic psychophysiological investigations aimed at finding essential mechanisms of good aborigines' adaptation to the extreme climatic and geographic conditions of the North.

That is why we present here a review of some results of research into the basic psychophysiological and cultural mechanisms of the aborigines' adaptation, which has been realized in the last few decades in the Northern regions of Russia.

\section{Traditional Way of Life of the Aboriginous Population}

Indeed, our and other experts' data [11] [12] suggest that the peoples of the North and other regions with uncomfortable and extreme climatic and geographic conditions have a peculiar mode of living and thinking, and their social and cultural values, as well as the perception of reality differ from those of the middle latitudes inhabitants. Even the language having common roots with many languages of kindred nations in the process of evolution takes a lot of new words expressing the concepts associated with major environmental factors of a particular region. For instance, the Nganasans, who live in the rigorous climate of the Taimir Peninsula, have a few hundred words expressing the concept of snow.

Formation of the Northern peoples' health took a lifetime of 3 - 5 thousand generations [4]-[6] [11]. From the early stages of human entry into the Polar regions, the natural environment substantially determined the conditions of peoples' existence. Changes in material culture, farming and housekeeping, the rhythms of eating, rest, reproduction, etc. were primarily dictated by the need for providing the maximum human vitality in extreme environmental conditions.

Popular wisdom assured efficient adaptation to extreme climatic and geophysical conditions of high latitudes by developing, since early childhood, an ability for figurative perception of the world, living in accord with nature, cultivating rhythms of activity and rest concordant with the biosphere, which contributed to maximum acceleration of recovery.

In general, it is known [12] that the indigenous peoples of Siberia and the North were able to most efficiently maintain their health, vital activity and reproduction in extreme climatic conditions through the selection of lifestyle, rituals, diets, regimes of work and rest, family and cultural traditions, the main types of crafts, clothes that conserve heat and favour a body self-purification, as well as through a number of psychotherapeutic (ritual, shaman) means, and products of animal and vegetable origin. It was a type of environmentally friendly way of life well-balanced with all the elements of the biosphere. At the same time, all human activities and nomadic way of life allowed for reproducing natural resources, flora and fauna of the ethnic territory.

Let us first consider the problem of work and rest for the indigenous population. Till now, many managers do not understand why a native resident of the North cannot adapt to the daily 8-hour working day, feels its early beginning, especially in winter, as a burden, cannot get used to the strict regulations for lunch breaks, etc. Physiological studies of the last 20 years [13] shed light on this problem. The situation springs from the residents of northern latitudes organisms' ability to mobilize, in a unit of time, their mental energy, plasticity, and information reserves during work and periods of recovery.

\section{The Types of Adaptive Response}

Normally, in a middle-latitude human population, there are three types of people, characterized by the ability for mobilizing internal resources in a unit time (Ibid.). One of them has the ability to mobilize the maximum internal reserves in response to powerful stressing factors in a short time and, thereby, to provide the most efficient short-term adaptation to the changed conditions of existence. In such situations, nervous processes in the people of this type are accelerated, the efficiency of information processing in brain structures increases, the speed of simple sensory motor reactions maximizes, adaptive stress hormones are released into the blood, activating the cardio-respiratory system, and also released into the blood are carbohydrates, proteins and fats needed for en- 
hanced energy supply. However, a rapid expenditure of internal resources does not mean the subsequent swift recovery. The recovery process also requires additional mental, plasticity, energy, and regulatory resources that have been already largely used for intense short adaptation. Because of this, the compensation of lost resources, as well as the rehabilitation of structural and functional elements of the life support systems in the individuals of the first type are delayed for a considerable time. Next efficient rapid mobilization of resources in the people of this type is possible only after the accumulation of a minimum of required resources. Kaznacheev [14] called the people with this high-speed type of adaptive response "sprinters", by analogy with sport. The above-mentioned scientist believes that the "sprinters", "under extreme changeability of the environment, pronounced fluctuations and inadequate conditions in the biosystem, must have a great safety margin" (Ibid., p. 21). Noteworthy is the fact [13] that it is just this type of adaptive behavior which enables an organism, practically from the first minutes of being under new conditions, to rebuild its psychological and physiological mechanisms of life support in such a way that allows a successful and adequate response to any changes in the environment, with the maintenance of a high level of mental and physical activity. But long living in extreme conditions depletes fast the adaptive resources of "sprinters". They begin to fall ill with frequent acute infections, neurodystonia, hypertension and other environmentally caused diseases [12] [13].

As to the opposite type of adaptive strategy, Kaznacheev supposes that “...under the conditions of prolonged influence of unfavourable factors, the most resistant are bound to be the systems capable of maintaining strained essential adaptive mechanisms for a long time" [14].

This opposite, second type of adaptive ability to mobilize internal resources is characterized by a more saving and slow use of body resources in a unit time [12] [13] [15]. The people of this type respond to a stressful situation by a gradual increase in the mobilization of central nervous and endocrine systems resources, metabolism, cardiovascular and respiratory systems, the immune protection, excretory and barrier functions. But the activation of all mental, regulatory, plasticity and energy resources does not reach the maximum possible values. The regulatory life-support system sets restrictions on the use of all the organism resources in a short period of time. The body maintains a constant reserve of adaptive resources that begins to grow already in the act of being used. These people consume and recover their adaptive resources concurrently. They are well adapted to the long-term effect of stressing factors which are not very intense. During the first months of adaptation the representatives of this type of adaptive behavior have significant complications in the functioning of basic homeostatic systems, reduced capacity for work, and a poor attitude of mind (a high level of anxiety, inhibition of neural processes, aggression, and depression). However, these people cannot adapt to dramatic stressful situations. Such situations may provoke in these people an adaptive frustration and often result in pathological conditions. These people are more susceptible to chronic diseases, which have a benign character. But the people of this type are less susceptible to acute illnesses and, in general, owing to their adaptive mechanisms they possess an advantage for survival in the North for a long time. Described people with the saving type of adaptive response may be called "stayers" [13].

Finally, there is a group of people with an average adaptive ability to mobilize internal resources, called a "mixed" one. The individuals of this group are not able to withstand a powerful short stress and long-term stress of medium intensity.

So, how the types of "stayers" and "sprinters" are related to the formation of psycho-physiological reactions in the native peoples of the North and their modes of work and rest? It turned out that they are related directly. Analysis of our research results [12] shows that among the townsmen and villagers of the Khanty-Mansi Autonomous Region there are more "stayers", and in the rural population which is less protected from extreme environmental factors, the proportion of "stayers" is significantly greater. These results agree with the data from other northern regions of Russia (Taimir, Yamal, Yakutia, the Komi Republic, and Chukotka) where natural selection has led to the accumulation of "stayers" in population, i.e., the people whose genophenotypical adaptive abilities allow them to live in extreme climatic and environmental conditions (Ibid.).

The data obtained in our research [16] confirm that the indigenous population of the North mainly belongs to the type of "stayers" and, accordingly, mobilizes their psychic, energy, plasticity and information life-supporting resources and uses them to ensure the gradual recovery processes in a saving mode. In this connection, it is clear why the North natives prefer to work in a slow time with less physical activities and reduced time intervals and, therefore, with prolonged recovery periods. In other words, the "stayer" adaptive type of indigenous population may provide the advantage of survival in extreme climatic and geographic conditions of high latitudes at a smooth functioning and moderate social, physical and mental stress. Intense socially prescribed rhythm of fixed 
8-hour labor, especially in winter, causes rapid exhaustion of internal organism's resources reducing the rate of recovery processes, as well as the development of the state of severe physical and mental overstrain. Neither emergency jobs and "records", norintense socio-economic rhythms of achieving material success in the realities of modern capitalism are compatible with the "stayer"-type abilities of mobilizing mental and physical resources of human organism. Therefore, the organism of this type subconsciously "protests" and "does not agree" with the imposed "sprint" pace of life (Ibid.).

\section{The Northern Type of Metabolism and the Formation of Nutrition Patterns}

Related to the described "stayer" adaptive type and the rate of recovery processes are also ethnic differences in the rate of digestion in indigenous population of the North, of recovery processes in the gastrointestinal tract and liver, and, accordingly, the rhythm of food intake [11] [12] [17]. Three-time (by a watch) eating is not inherent in the true northern latitudes natives, who are following the traditional way of life. Can you imagine a hunter, fisherman or reindeer-breeder, an aboriginal of the North, during their fishing or hunting, who eats at a strictly fixed time in tundra, taiga, or on the open sea? In fact, a person takes food only when the previous portion is digested enough for the one begins to feel hungry. In exactly the same way, wild animals start to hunt only after digestion of the previous prey and the appearance of hunger. Besides, the rate of digestion and regenerative capacity of the digestive system in the North are limited by decreased activity of digestive and other enzymes caused by conformational changes in the protein structure of the enzyme under the influence of powerful geomagnetic disturbances and fluctuations of the gravitation force in high latitudes. It is no coincidence that almost all the nations of the North routinely use as a remedy dried stomachs of birds, hares and other animals, as well as dried fish gall-bladders [16].

Assessing the peculiarities of food-taking mode, we should dwell on the laws of the formation of nutrition patterns of the indigenous population in the North [11] [12] [17]-[19]. An important place in ensuring the adequate adaptation of indigenous population to extreme conditions of the North is occupied by alimentary processes of life supporting based on the diets appropriate to the northern protein and fat metabolism type. This type of metabolism has been formed as a protective adaptive response of the body to a so-called Polar stress syndrome comprising the complex of adaptive and disadaptive changes in the human body, beginning with molecular membrane, enzymatic, and metabolic processes and ending with the reactions of the central nervous system under the influence of extreme geophysical, climatic and meteorological conditions in high latitudes [20][23]. Just the peculiarities of life-supporting body systems functioning under the Northern environmentally caused stress (Polar stress syndrome) have demanded greater use of proteins and fats in metabolism and a reduction of carbohydrates, which correspond to a predominance of northern and marine mammals meat, birds, and fresh, often raw fish in traditional diets.

Up till now, the rejection of European "civilized" diets by many aboriginals is associated, above all, with a deficit of essential amino acids in imported products, as well as of sufficient amounts of polyunsaturated omegatriene fatty acids and specific biologically active substances generated or accumulated in the organisms of animals and fish for achieving a good balance with the natural factors and better adaptation to specific climatic conditions of the North [21] [22].

Panin [20] [21] [24] [25], summarizing a series of studies, notes that in high latitudes, under the influence of severe environmental factors, a human body generates a new level of homeostasis characterized by greater use of fat and less carbohydrates for energy needs. This significantly increases the role of protein in energy metabolism. A demand for water-and fat-soluble vitamins also changes in favour of the fat-soluble ones. Similar evidence of the protein-lipid metabolism orientation in the aboriginals of the North is present in [26]-[36].

Less need for carbohydrates in the indigenous population is confirmed by many studies. It is believed that the steady decline in the level of glucose is one of the earliest metabolic manifestations of the formation of longterm adaptation.

Such predilections are evident in the recipes of traditional medicine [11]. As an effective medicinal and sanitation remedy for many diseases it is customary to use the fresh blood of healthy deer, fattened, with thick hair and antlers, and brilliant eyes. Part of the blood is usually frozen and thus laid in for future use. To restore strength and to provide a tonic effect it is proposed to use the nutrient mixture consisting of finely chopped raw liver of a just killed animal and cranberries or red bilberries.

In common usage as a preventive measure, are sliced frozen meat and fish oil. For disease prevention and as a 
medicine it is proposed to use melted reindeer fat (1 - 2 tablespoons, or about $60 \mathrm{~g}$, once a day). Some recommendations state that the fat should be taken from the small intestines of a reindeer. In some cases, for therapeutic and preventive purposes it is recommended to use warm melted inside fat of polar foxes (a tablespoon three times a day, in case of children a teaspoon, between meals). A stock of fat is laid in autumn and winter (Ibid.).

Beluga fat is used for greasing poorly healing wounds and painful bruises. It promotes rapid healing and relieves pain. Many peoples of the North use bear and goose fat. As remedies are also used tundra partridge meat, sliced frozen reindeer liver, fresh reindeer lung and the marrow from reindeer lower extremities (Ibid.).

Even berries and cedar nut kernels are stored and consumed by mixing them with cod-liver oil. For example, crowberries are eaten with seal oil and dried fish (Ibid.).

All the above supports the conclusion that the indigenous population prefers protein and fatty food-stuffs. So, during the formation of the "high-latitude" adaptation type of the indigenous population of the North, a specific version of the "Polar metabolism" has developed. This type of metabolism is characterized by increased energy role of lipids and proteins, whereas the role of carbohydrates coming from the environment decreases. The basic human energy balance in high latitudes is provided by lipid metabolism, and the proportion of energy derived from the oxidation of carbohydrates remains relatively small [22].

The inhabitants of the temperate zone use this type of metabolism as a reserve one: it can be engaged periodically in cases when the body needs to receive a great deal of energy.

Comparison of diets of the indigenous population of the North allows us to say with confidence that the Polar type of metabolism is inherent in almost all the aboriginal Northern peoples [20]-[22].

It is clear that the energy-saving type of adaptive reserves mobilization in the indigenous inhabitants of the North and resulting from this type mental, emotional and physiological reactions, metabolic processes, modes of work and rest, the rhythm of digestive processes and eating have defined over centuries of living in high latitudes and forming a peculiar way of life, including a complex of family, community, cultural traditions and harmonizing human activity with varying severe natural conditions of existence [12].

This way of life is in many respects exactly the opposite of that in the technocratic civilization. The most advanced school education systems that are effective in the middle-latitudes in the North lays the obstacles to the development of image-bearing world perceiving and imaginative creative thinking, which for the northerners are ones of the most important adaptive protection mechanisms.

At the same time, imbibed from the birth faith in the efficacy of rituals allows shamans and healers to cure many ailments in the indigenous population of the Northern regions through the use of ritual psychotherapeutic effects. That is why the aboriginal peoples of the North, despite numerous bans by "highly civilized" Europeans, are unwilling to accept European food rations, feel as a burden the work in organized groups of modern enterprises and institutions, hardly agree with the settled way of life, still retain the rituals and institutions of shamanism which determine the basic principles of life support and the survival in extreme climatic and geographic conditions of high latitudes (Ibid.).

In other words, we are dealing with the Northern adaptive type of the human body that adapts itself to the unfavourable environmental conditions of the North due to the tuning of psychological and physiological body functions as well as due to a fundamental change in culture and way of life [22].

\section{Functional Hemispheric Asymmetry}

One of the most important elements of evolutionarily selected mechanisms of indigenous population's adaptation to extreme climatic and geographic conditions of the North was the formation of genophenotypically fixed asymmetric functioning of the cerebral hemispheres [11].

Modern scientific data clearly indicate leading role of the right hemisphere in the regulation of adaptive tuning of the human body to the changing conditions of the environment and the effects of other physical, including technogenous, factors [12]. This conclusion is supported by a significant increase in the proportion of lefthanders among the people living in the regions with extreme climatic conditions (compared with those with a favourable temperate climate); the dominance of the right cerebral hemisphere in the indigenous population of the North; dropping out, with an increase in residence in high latitudes, of aliens with left hemisphere dominance; an increase of the people with right hemisphere dominance among the first and subsequent generations of immigrants to the North.

In the indigenous population of Taimir, 56.3\% reveales right hemisphere dominance. Manifest left-handers, 
which even at school continued to write and paint by left hand despite of urgent attempts to teach them anew, ran to $21.6 \% .54 .5 \%$ of them had left-handed relatives (father, mother, brothers, and sisters) [36].

Among mixed- and right-handers, 23.3\% had left-handed relatives. Material culture, lifestyle, psychological structure of activities in work and family life of many Northern peoples also are not related to the dominance of the left hemisphere. For example, a reindeer sled, throwing a maut (belt loop), etc. suggest just the left hand as a leading one. Other arte facts are not clearly designed for the right hand. This distinction is important because the development of the objective environment and way of life of the European peoples living in middle latitudes is characterized by the increasing complexity of social structures and the specialization and unification of tools designed for leading right hand. In the North, newcomers comprising immediately after their arrival at high latitudes only $6 \%$ - $7 \%$ of left-handers, under the influence of unfavourable environmental factors, are subject to natural selection. Right-handed people are little by little beginning to leave the North. Among those who remain, there are more mixed- and left-handers. So, in Taimir, among the aliens who have lived for 15 - 20 years in high latitudes, the number of left-handers reaches $17.9 \%$ (Ibid.).

During the Soviet-Indian Polar experiment [37], it was also found that the success of adaptation, in regard to both a healthy population of the tropics, and the inhabitants of the middle latitudes in the North, depends largely on the activation of the right hemisphere against the background of increasing activity of the central nervous system as a whole. In addition, it was shown that in the people working and living in extreme climatic and geophysical conditions of the environment, high functional activity of the right hemisphere is associated with the effective type of metabolism, high resistance to emotional stress, good immune protection, and balance of endocrine responses, optimal recovery processes, as well as a more favourable course of pathological processes. When finding themselves under the adverse effect of changes in climatic factors, the people with left hemisphere dominance to a greater extent suffer from rapidly progressing diseases, are subject to psycho-emotional stresses and metabolic disorders, they are also characterized by painful meteo sensitiveness, functional immunodeficiency, and inadequacy of regenerative plasticity. In other words, the function of the right hemisphere of the human brain is associated with the mechanism of developing resistance to natural (solar, geophysical and meteorological) environmental conditions. A manifestation of this stability is the resistance to meteopathological reactions.

Studies made it possible to conclude that the right hemisphere, controlling the internal homeostatic processes in the body and rearranging them in line with changes in the external environment, provides the biological mechanisms of natural adaptation. In contrast, the left hemisphereis to a greater degree responsible for social adaptation [12].

In this regard, it is concluded that adequate adaptation to extreme environmental conditions is possible only at a sufficiently high functional activity of the right hemisphere and, at the same time, an unreduced function of the left hemisphere. The function of both hemispheres and their blood supply must not be below the physiological optimum. The regulative role of the right hemisphere in the restructuring of adaptive processes in response to changing environmental factors consists in the activation of neuroendocrine, energy, immune, functional and biophysical mechanisms of homeostasis (Ibid.).

In our opinion, the origins of a particular specialization of the cerebral hemispheres for the adaptation to natural and socializing factors should be searched since the time distant from us for many thousands of years. Fundamentals of the functioning of the right hemisphere as a regulative mechanism for adaptation to natural physical factors are hidden in the mists of time. Indeed, the life of man since the dawn of civilization has been linked to a permanent need for survival in an extreme environment. Life in the nature forced exactly the work of the parts of the brain that are responsible for receiving and processing information on the natural environment, flora and fauna. Exposure to high and low temperatures, the sounds associated with the phenomena of nature, various visual images of flora and fauna constantly demanded increased functioning of the right hemisphere and contributed to its improvement (Ibid.).

Subconscious feeling of the importance of natural phenomena and the lack of real understanding of the world ultimately forced people to deify the various phenomena of nature and give each of them the image of God. Think of the Aesir in many nations, symbolizing the sun, moon, water elements, nature, rain, wind, thunder, and seasons. Smaller deities personified trees, springs, streams, etc. Over thousands of years a culture was being built up that is aware of its unity with the processes of nature, humanity's dependence on these processes and understands the need of concordance of all the human activity, all the life with natural phenomena [11].

The same ideas, to some extent being assimilated at the genetic level, laid at the heart of people's respect for 
nature. The pagan religions and cults of that time strengthened this attitude and made people associate in their reflections successes in agriculture, hunting, in a healthy conception of children and other affairs of everyday life with strict observance of the rules of coordination of all initiatives with the periodicity and characteristics of natural phenomena. Our ancestors assigned to these phenomena the change of seasons, weather processes, the laws of motion of the stars, the sun and the moon. The mankind learned a great deal from the nature, and religious worships preserved this knowledge. In fact, worship of many gods embodied, during the huge period of mankind's development, canonical knowledge of the interactions between man and nature, that is, the knowledge that is now reopened by science.

It seems to us that the practical significance of such an attitude to nature for survival under adverse climatic and geophysical conditions in some regions of the Earth has maintained cults of that kind and related cultures for thousands of years to the present day among many indigenous peoples of the world. This path is shared by all the Eastern nations founding their social and technological development on accordance with the laws of nature. Most likely, just these processes are the cause of retaining in the part of humanity right-hemisphere regulation of biological adaptation showing its high-performance in extreme natural habitat. In general, we are dealing with not only the biological and psycho-physiological adaptive processes in human body [12].

We should mean also this particular view of the world, the psychology of behavior that harmonizes the man and his activity with natural phenomena, a subconscious perception of changes in the nature and a forestalling response to these changes, as well as culture, language, way of life, and the formation of special life-support systems that have allowed people to survive for thousands of years without electricity, gas, oil, cars and steamheating, and to conserve during all that time quite poor, but very necessary for people natural resources of high latitudes. Psychics of a significant number of the aborigines with right hemisphere dominance features a high emotional stability, steadiness, a low rate of reaction to external stimuli. Such people avoid a rapid pace of life and an acceleration of many physical and mental functions. They are patient and never in a hurry. Emotional and creative thinking of the indigenous population of the North provides spontaneity of seeing the world as it really is.

Considering the features of the cerebral hemispheres functioning in the indigenous population of the North it is necessary to touch upon a subject of a hemispheric asymmetry with respect to the resistance to emotional stress. It is shown that the largest reserves of adaptation to extreme climatic and geophysical conditions are characteristic of people with right hemisphere dominance and normal functional activity of the left hemisphere. The northerners with a high activity of the right hemisphere felt emotional stress more than $28.0 \%$ lower than in the case of low activity of this hemisphere. The characteristics of this people were lower psycho-emotional stress, less inhibition of nerve processes, lower emission of cortisol into the blood, the best indicators of blood supply to organs, less intense excretory, detoxification and metabolic functions, a lower frequency and less manifestation of pathological disorders, and greater resistance to changes of meteogeophysical factors, which is indicative of good organism's ability to tune in advance internal life-supporting processes to meet changing natural and cosmic factors [12] [37].

Reduced function of the right hemisphere (below the physiological optimum) becomes one of the main causes of negative emotional stress accompanied by either depression or aggression, various black emotions, high levels of anxiety, inhibition of nerve processes, tendency to conflicts, dissatisfaction with the actions of other people, a bad mood, increased blood pressure, poor health, mental instability and decreased mental and physical efficiency. When emotional stress occurs at insufficient function of the cerebral hemispheres, it becomes an important element in the development of pathological conditions in humans.

\section{Conclusion}

Thus, with the data on the regulatory role of the right hemisphere in the aboriginals of the North, we can assume that it is the functional activity of this hemisphere that determines physiological response to perturbations of weather, gravity, geomagnetic and other factors of the biosphere, being one of the main regulatory mechanisms for the formation of adaptive resistance to unfavourable environmental conditions in high latitudes [13].

\section{References}

[1] Bromley, Yu.V. (1983) Essays on the Ethnic Theory. Science, Moscow.

[2] Gumilev, L.N. (1993) Ethnogenesis and the Biosphere of the Earth. Michelle and Co., Moscow. 
[3] Bromley, Yu.V. and Markov, G.E., Eds. (1982) Ethnography. A Primer. Higher School, Moscow.

[4] Alexeeva, T.I. (1977) The Geographical Environment and Human Biology. Thought, Moscow.

[5] Alexeeva, T.I. (1986) Adaptive Processes in Human Populations. Moscow State University Press, Moscow.

[6] Alexeeva, T.I. (1998) Human Adaptation to Different Ecological Niches of the Land. Biological Aspects. MNEPU Publication House, Moscow.

[7] Agadzhanian, N.A. and Ermakova, N.V. (1997) Portrait of a Man in the North. Circle, Moscow.

[8] Sukharev, A.V. (1997) An Introduction to the Philosophical and Methodological Foundations and Conceptual Apparatus of Ethnofunctional Approach in Psychology. Ethnic Psychology and Society, IEA RAS, Moscow, 417-429.

[9] Sukharev, A.V. (1995) The Role of Ethnic Conditions in Violation of Mental Adaptation and Reproduction. Ethnodemographic Features of Reproduction of the Peoples of the Russian North. IEA RAS, Moscow, 233-254.

[10] Sukharev, A.V. (1998) Ethnofunctional Approach in Psychology. Methods of Experimental Psychological Field Research. Appl Psychol Psychoanal, 3, 18-30.

[11] Hasnulin, V.I., Wilhelm, V.D., Skosyreva, G.A. and Povoroznyuk, E.P. (1999) Modern View of the Traditional Medicine of the North. SB RAMS, Novosibirsk.

[12] Hasnulin, V.I., Wilhelm, V.D., Zyryanov, B.N., Selyatitskaya, V.G., Kulikov, V.Yu., Hasnulin, P.V. and Egorova, G.M. (2004) Medical and Ecological Bases of Formation, Treatment and Prevention of Diseases in the Indigenous Population of the Khanty-Mansi Autonomous Region. A Handbook for Physicians, SB RAMS, Novosibirsk.

[13] Hasnulin, V.I. and Hasnulina, A.V. (2013) Stress in the North. Mechanisms of Resistance to Emotional Stress. LAP LAMBERT Academic Publication.

[14] Kaznacheev, V.P. (1980) Modern Aspects of Adaptation. Science, Novosibirsk.

[15] Anthny, R. (2013) Animistic Pragmatism and Native Ways of Knowing: Adaptive Strategies for Overcoming the Struggle for Food in the Sub-Arctic. International Journal of Circumpolar Health, 72, 811-817.

[16] Hasnulin, V.I., Leutin, V.P., Chuhrova, M.G. and Gafarov, V.V. (2009) Ethnocultural Factors of Mental Adaptation of the Natives of Siberia and the North in Modern Conditions. World of Science, Culture, Education, 6, 248-254.

[17] Hasnulin, V.I., Filipchenko, R.E. and Hasnulina, A.V. (1987) Polar Metabolic Type and Approaches to Correction of Disadaptation and Pathological Changes in the Far North by Means of Food. In: Food as a Basis for Primary Prevention of Diseases in the North, SB RAMS, Novosibirsk, 42-49.

[18] Duffy, L., Gerlach, C., Ebbesson, S., Young, K., Dewailly, E., Byerregard, P., Dunlap, K., Goddahn, A. and Reynolds, A. (2013) Arctic Medical Health, Disease and Nutrition: The Challenges and Joys. International Journal of Circumpolar Health, 72, 841.

[19] Ebbesson, S., Higgins, P., Voruganti, S., Devereux, R., Fabsitz, P., Howard, B., Umans, J. and Comuzzie, A. (2013) Saturated Fatty Acids Are Associated with CVD Risk Factors: The Gocadan Study. International Journal of Circumpolar Health, 72, 353-354.

[20] Panin, L.E. (1983) Biochemical Mechanisms of Stress. Science, Novosibirsk.

[21] Panin, L.E., Berezovikov, P.D. and Andronova, T.I. (1983) Clarification of the Physiological Norms for Nutrients and Energy for Different Climatic Zones of the East of the USSR. Medical and Biological Aspects of the Food Program in the East of the USSR, SB RAMS, Novosibirsk, 3-53.

[22] Hasnulin, V.I. (2009) Health, Northern Type of Metabolism and a Need for Fish in the Diet in the North. Problems of Health Preservation in the North and Siberia. Proceedings on Medical Anthropology, News Press, JSC, Moscow, 58-77.

[23] Cardel, M., Lemas, D.J. and Fernanandez, J.R. (2013) Greater Consumption of Polyunsaturated Fatty Acids Are Related to Increased Lean Mass and Decreased Visceral Adiposity in a Multi-Ethnic Sample of Children. International Journal of Circumpolar Health, 72, 837-838.

[24] Panin, L.E., Berezovikov, P.D. and Andronova, T.I. (1987) Normal Human Needs for Nutrients and Energy for the Regions of Siberia and North Asia. Food as a Basis for Primary Prevention of Diseases in the North, SB RAMS, Novosibirsk, 29-42.

[25] Panin, L.E. (2005) Stress, Heart and Blood Vessels. Questions of Atherogenesis, SB RAMS, Novosibirsk, 20-35.

[26] Khaltaev, N.G., Klochkova, E.V. and Tikhonov, A.V. (1984) Nutrition and Risk Factors of Coronary Heart Disease in Men of the Chukotka Autonomous Region. Cardiology, 4, 62-67.

[27] Vloschinsky, P.E. (1999) Status of Carbohydrate and Fat Metabolism, and Its Relationship with the Structure of Nutrition among the Residents of the Far North. Synopsis of Thesis for a Doctor's Degree, Novosibirsk.

[28] Vloschinsky, P.E., Panin, L.E. and Kolosova, N.E. (1994) The Effect of Nutrition on Biochemical Indicators of Blood in the Asian Population of the North. Journal of Medical Sciences, 2, 21-24. 
[29] Boyko, E.R. (1990) Metabolic Features of the Representatives of the National Minorities of the North. Synopsis of Thesis for a Candidate's Degree, Tashkent.

[30] Boyko, E.R. (2005) Physiological and Biochemical Basis of Human Life in the North. Ural Branch RAS, Ekaterinburg.

[31] Boyko, E.R. and Ramenskaya, E.B. (1990) The Influence of Lifestyle on Endocrine and Metabolic Profile of the Representatives of the Indigenous Peoples of the North. In: Socio-Economic Development and the Health of Indigenous Peoples of the North, Abstr., Krasnoyarsk, 20-21.

[32] Kozlov, A.I. (2002) Ecology of Nutrition. A Course of Lectures. MNEPU Publishing House, Moscow.

[33] Kozlov, A.I., Borinskaya, S.A., Sokolova, M.I. and Zdor, E.V. (2006) Intake of Dietary Sugars and Carbohydrates in the Metabolism of the Indigenous Population of the North. The 13th International Congress on Circumpolar Health, Materials, Novosibirsk, 147-148.

[34] Kozlov, A.I. and Vershubskaya, G.G. (1999) Medical Anthropology of the Indigenous Population of the North of Russia. MNEPU Publishing House, Moscow.

[35] Khamnagadaev, I.I. (1991) Nutrition of the Indigenous Population of Yakutia. Actual Problems of Cardiology in the North and Siberia, Abstr., Krasnoyarsk, 131-132.

[36] Hasnulin, V.I., Stepanov, Y.M. and Shestakov, V.I. (1983) Functional Asymmetry and Human Adaptation in the Far North. Bull SB AMS USSR, 2, 27-30.

[37] (1994) Medical and Environmental Aspects of the Adaptation of the Inhabitants of the Tropics to the Arctic (Based on the Soviet-Indian Experiment). Vol. 1, SB RAMS, Novosibirsk, 2. 
Scientific Research Publishing (SCIRP) is one of the largest Open Access journal publishers. It is currently publishing more than 200 open access, online, peer-reviewed journals covering a wide range of academic disciplines. SCIRP serves the worldwide academic communities and contributes to the progress and application of science with its publication.

Other selected journals from SCIRP are listed as below. Submit your manuscript to us via either submit@scirp.org or Online Submission Portal.
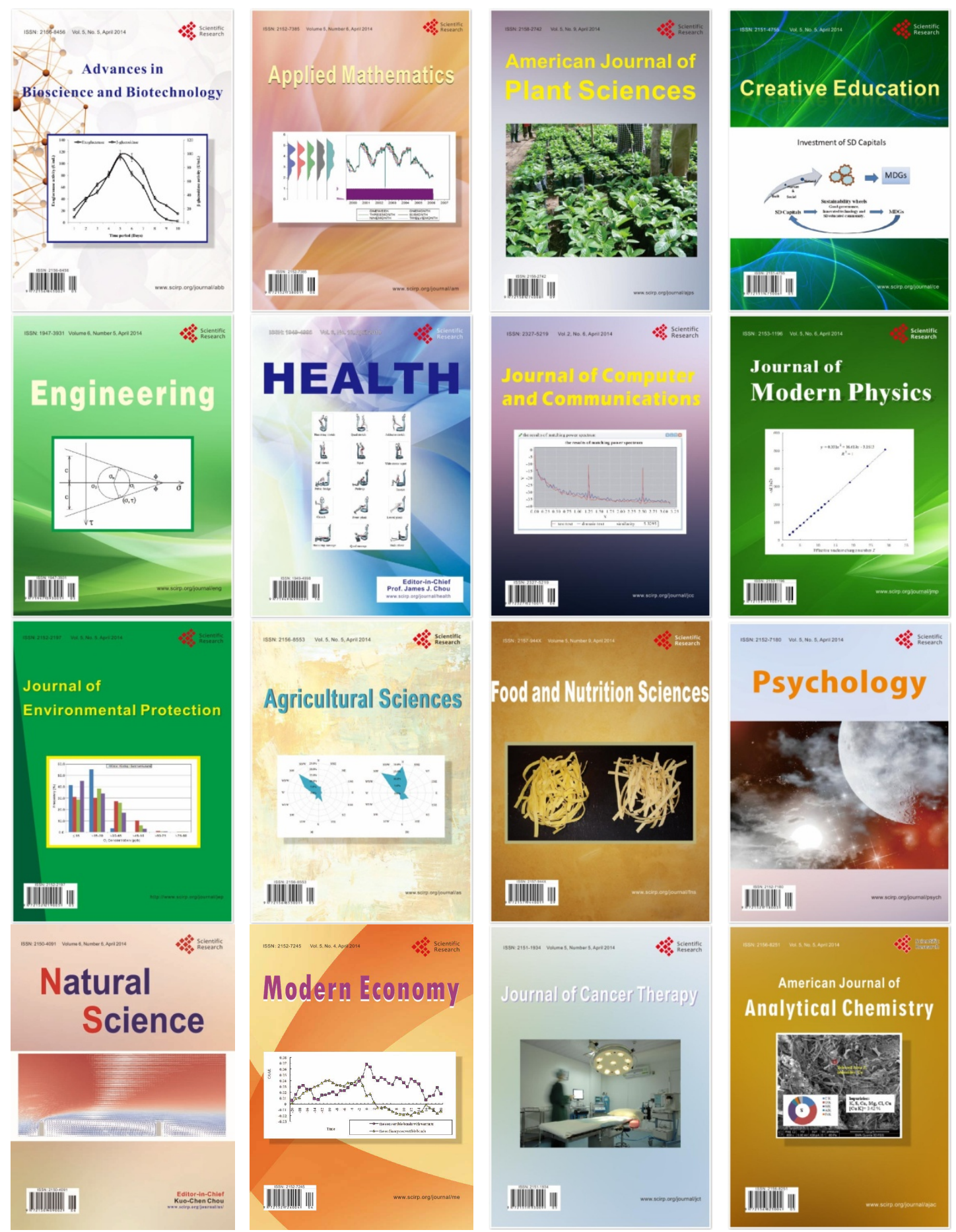